УДК 616-002.5-097-08-039.76-06:616-002

DOI: $10.26435 /$ UC.V0I1(38).364

\author{
Е.В. Корж${ }^{1}$, Н.А. Подчос ${ }^{2}$, Л.В. Стрига², Т.С. Извекова ${ }^{3}$, Н.А. Малявко \\ ${ }^{1} Г 00$ ВПО «Донецкий национальный медицинский университет имени М. Горького», Донецк \\ 2Республиканская клиническая туберкулезная больница, Донецк \\ 3Городской противотуберкулезный диспансер, Донецк \\ ${ }^{4}$ Городской противотуберкулезный диспансер, Макеевка
}

\title{
ВЛИЯНИЕ АНТИРЕТРОВИРУСНОЙ ТЕРАПИИ НА СОСТОЯНИЕ БОЛЬНЫХ КО-ИНФЕКЦИЕЙ ТУБЕРКУЛЕЗ/ВИЧ С ГЛУБОКОЙ ИММУНОСУПРЕССИЕЙ НА РАЗЛИЧНЫХ ЭТАПАХ НАБЛЮДЕНИЯ
}

По современным представлениям, лечение ВИЧ-инфекции с применением антиретровирусной терапии (AРT) целесообразно начинать вне зависимости от содержания CD4-лимфоцитов [1]. При формировании глубокой иммуносупрессии АРТ является главным условием сохранения полноценной жизни за счет эффективной профилактики множества оппортунистических инфекций, в том числе и туберкулеза (ТБ). Развитие активного туберкулеза у ВИЧ-инфицированного человека диктует необходимость раннего начала АРТ, которую, по мнению большинства авторов, следует начинать не позднее, чем через 2-3 недели от начала приема противотуберкулезных препаратов [2-4]. Присоединение АРТ больным ко-инфекцией ТБ/ВИЧ с выраженным дефицитом Т-хелперного звена сопряжено с риском развития воспалительного синдрома восстановления иммунной системы (СВИС), который заключается как в обострении ранее диагностированного и пролеченного туберкулеза, так и в развитии новых оппортунистических инфекций (ОИ) в период от первых дней до нескольких месяцев после начала противовирусного лечения [4-6]. Отсутствие или позднее начало АРТ особенно опасно на стадии выраженного иммунодефицита Т-хелперного звена иммунитета, когда течение туберкулезной инфекции имеет склонность к генерализации, поэтому, несмотря на существующие риски, считается, что присоединение АРТ больным, получающим лечение туберкулеза, повышает шансы на эффективное излечение [7, 8].

\section{ЦЕЛЬИССЛЕДОВАНИЯ}

Проанализировать влияние АРТ на состояние больных ко-инфекцией ТБ/ВИЧ с глубокой иммуносупрессией на различных этапах наблюдения.

\section{МАТЕРИАЛ И МЕТОДЫ}

Были изучены результаты обследования 139 больных ко-инфекцией ТБ/ВИЧ, находившихся на лечении в Республиканской клинической туберкулезной больнице г. Донецка в 2011-2018 гг., которым в отделении была начата АРТ. Для исследования были отобраны пациенты с содержанием CD4-лимфоцитов не более 100 кл/мкл, средний возраст составлял $(38,1 \pm 2,4)$ лет, мужчин было 90 (64,7\%). Медианы процентного и абсолютного содержания в крови CD4 составляли соответственно 4,2\% и 33,2 кл/мкл, вирусной нагрузки - 450014 РНК-копий/мл (62 определения). Впервые болели туберкулезом 118 человек $(84,9 \%), 21$ больной $(15,1 \%)$ получал повторное лечение по поводу рецидивов туберкулеза (РТБ) и неудачи лечения (НЛ). Всем пациентам начинали химиотерапию туберкулеза в интенсивной фазе (ИФ) противотуберкулезными препаратами (ПТП) 1 ряда (изониазид, рифампицин, пиразинамид, этамбутол), у 59 (42,4\%) больных применяли препараты 2-го ряда (фторхинолоны, аминогликозиды или капреомицин, протионамид/этионамид, циклосерин, парааминосалициловую кислоту): в 12 (20,3\%) случаях - по поводу мультирезистентности (одновременная устойчивость как минимум к изониазиду и рифампицину) микобактерий туберкулеза (МБТ), в 43 (72,9\%) - в связи с другими вариантами устойчивости, в 4 (6,8\%) - для усиления схемы лечения по жизненным показаниям до получения результатов теста лекарственной чувствительности (ТЛЧ). Всем пациентам проводили профилактику оппортунистических инфекций (ОИ) согласно протоколу, АРТ назнача-

(c) Е.В. Корж, Н.А. Подчос, Л.В. Стрига, Т.С. Извекова, Н.А. Малявко, 2021

(c) Университетская Клиника, 2021 
ли по стандартной схеме для наивных пациентов, включающей 2 нуклеозидных и 1 ненуклеозидный ингибиторы обратной транскриптазы [1]. Оценивали результаты рутинного лабораторного и рентгенологического обследования, данные спиральной компьютерной томографии (СКТ) органов грудной клетки (ОГК). Для выявления бактериовыделения выполняли микроскопию мазков мокроты на наличие кислотоустойчивых бактерий (КУБ), посев на жидкую среду Миддлбрук на аппарате ВАСТЕС и твердую среду Левенштейна-Йенсена, при росте культуры МБТ проводили ТЛЧ к противотуберкулезным препаратам (ПТП) 1-го и 2-го ряда. Дальнейшую судьбу пациентов, выбывших из стационара, проследили у 89 человек, период наблюдения составил более восьми лет: с января 2011 г. по май 2019 г.

Статистическую обработку полученных данных проводили с использованием пакета MedStat (лицензионный № MS 000029) [9]. Полученные данные представляли в виде медианы, качественные характеристики - в виде частоты встречаемости признака (\%).

\section{РЕЗУЛЬТАТЫ И ОБСУЖДЕНИЕ}

На момент госпитализации состояние пациентов характеризовалось выраженной интоксикацией, истощением, частым развитием распространенных туберкулезных процессов в легких и генерализованных форм туберкулеза (см. табл.). Как видно из таблицы, после легких наиболее часто поражались лимфатические узлы, из клинических форм легочного туберкулеза преобладал диссеминированный, почти у половины пациентов при жизни имелись признаки генерализации процесса. Несмотря на редкое развитие деструкций, бактериовыделение всеми методами было обнаружено более чем у половины больных; по данным выполненных ТЛЧ, ча- стота мультирезистентного туберкулеза (МРТБ) составляла $17,1 \%$.

APT начинали после уменьшения явлений интоксикации, достижения хорошей переносимости препаратов и высокой приверженности к лечению. Перед началом АРТ больные приняли от 5 до 150 (медиана 39) доз ПТП. Присоединение АРТ сопровождалось развитием воспалительного СВИС у 48 (34,5\%) больных в сроки от 3 до 90 дней (медиана 16,0) после начала АРТ. Преобладал парадоксальный ТБ-СВИС - 41 (85,4\%) случай, СВИС в виде проявления (обострения) других ОИ наблюдали в 7 (14,6\%) случаях. Летальность от СВИС составила 14 (29,2\%) случаев, в структуре фатальных исходов 9 (64,3\%) случаев составлял туберкулез нервной системы.

Изучение эффективности стационарного этапа лечения показало, что $72(51,8 \%)$ человека успешно закончили ИФ противотуберкулезной химиотерапии и были выписаны для лечения в поддерживающей фазе (ПФ), $27(19,4 \%)$ продолжили ИФ в амбулаторных условиях, 9 (6,5\%) закончили полный курс и были переведены в диспансерную категорию наблюдения (кат. 5.1), 5 (3,6\%) самовольно покинули отделение, 4 (2,9\%) были переведены в другие медицинские учреждения без изменения диагноза, 2 больным выставили неудачу лечения и назначили повторный курс противотуберкулезной химиотерапии. Госпитальная летальность составила 14,4\% (20 больных): в 14 (70,0\%) случаях летальный исход наступил в результате СВИС, остальные пациенты умерли от прогрессирования туберкулеза, в том числе четверо - от мультирезистентного.

После выписки из отделения отдаленные последствия противотуберкулезной химиотерапии и АРТ зависели от длительности наблюдения (см. рис.).

Так, в 2011-2013 гг. были выписаны из отделения 32 человека, из них на начало 2019 г. в живых оставались пятеро (15,6\%), все они не пре-

Клиническая характеристика больных ко-инфекцией ТБ/ВИЧ на момент поступления в отделение

Таблица.

\begin{tabular}{lcc}
\hline \multicolumn{1}{c}{ Показатели } & Абс. значения & $\%$ \\
\hline \hline Туберкулез легких, & 133 & 95,7 \\
в том числе диссеминированный & 88 & 66,2 \\
\hline Наличие деструкций в легких & 40 & 28,8 \\
\hline Туберкулез лимфатических узлов & 102 & 73,4 \\
\hline Туберкулезный менингит & 27 & 19,4 \\
\hline Генерализованный туберкулез & 68 & 48,9 \\
\hline Бактериовыделение (всеми методами) & 81 & 58,3 \\
\hline Выполнено ТлЧ, & 70 & 50,4 \\
из них мультирезистентность & 12 & 17,1 \\
\hline
\end{tabular}




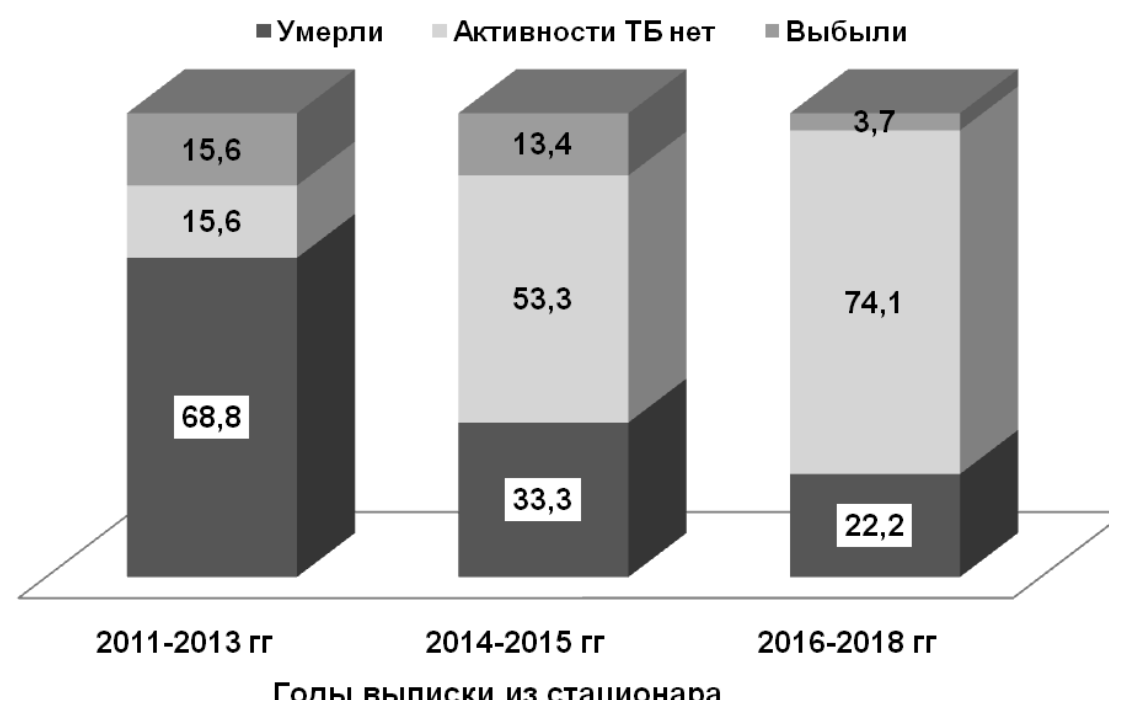

Рис. Отдаленные последствия противотуберкулезной и антиретровирусной терапии у больных ко-инфекцией туберкулез/ВИЧ в зависимости от продолжительности наблюдения,\% случаев.

рывали АРТ (длительность приема препаратов составляла 5,5-7 лет), при последнем определении удельный вес CD4 находился в диапазоне от 16,4 до 35,5\% (медиана - 28,5\%), в абсолютных значениях - от 351,0 до 660,0 кл/мкл (медиана - 502,0 кл /мкл), вирусная нагрузка была менее 50 РНК-копий/мл. Столько же больных выбыло из-под наблюдения. Умерли 22 человека $(68,7 \%)$, из них 13 (40,6\%) - в течение первого года после выписки. Основной причиной смерти был туберкулез - 14 (63,6\%) случаев (неудача лечения - 10 случаев, рецидивы - 4 случая), в том числе в 7 случаях выявлена мультирезистентность, в 2 - устойчивость к изониазиду при сохраненной чувствительности к рифампицину. Оставшиеся больные погибли от соматических заболеваний и бытовых инцидентов (по три случая), от ВИЧассоциированных заболеваний (два случая). Из умерших больных прервали АРТ девять (40,9\%) человек.

Следующие 30 пациентов были выписаны в 2014-2015 гг., период наблюдения составил 4-5 лет. На начало 2019 г. оставались в живых 16 лиц (53,3\%), они продолжали получать АРТ (двое возобновили прием после перерыва), активности туберкулезного процесса зафиксировано не было. Из группы этого периода наблюдения в СПИД-центре обследованы 14 человек: содержание CD находилось в пределах от 14,0\% до 35,5\% (медиана - 22,6\%), в абсолютных значениях - от 33,0 кл/мкл до 605,0 кл/мкл (медиана - 279,0 кл /мкл), вирусная нагрузка была менее 50 РНК-копий/мл, у 12 человек содержание CD4 превышало 100 кл/мкл. Выбыли из-под наблюдения четверо больных. Умерли 10 (33,3\%) человек, из них семеро - в течение первого года по- сле выписки. Среди причин смерти туберкулез составлял три случая (в том числе один - МРТБ), от бытовых инцидентов погибли трое больных, от ВИЧ-ассоцированных заболеваний и соматической патологии - по два человека. Из умерших пациентов прервали АРТ четверо.

Следующий этап наблюдения составлял 1-3 года для 27 пациентов, выписанных из отделения в 2016-2018 гг. Из них 20 (74,1\%) человек закончили полный курс противотуберкулезной химиотерапии, наблюдались у фтизиатра и не имели признаков активности туберкулезного процесса. Из выживших пациентов не прерывали АРТ 18 (90,0\%), содержание CD4 (обследованы 19 человек) составляло в процентах 6,1\% - 33,4\% (медиана 17,8\%), в абсолютном количестве 60,0-660,0 кл/мкл (медиана - 369,0 кл/мкл), уровень CD4 превышал 100 кл/мкл у 16 (84,2\%) человек. Вирусную нагрузку исследовали у 18 больных, она составляла менее 50 РНК-копий/ мл у 16 (88,9\%) лиц. Выбыл из-под наблюдения один $(3,7 \%)$ больной. Шесть $(22,2 \%)$ пациентов умерли: двое - от МРТБ, и четверо - от ВИЧассоциированных заболеваний, из умерших пациентов пятеро прервали АРТ.

Таким образом, прогноз туберкулеза у ВИЧинфицированных больных с глубокой иммуносупрессией зависел от адекватной антимикобактериальной химиотерапии с учетом данных ТЛЧ и приверженности пациентов к лечению. Начало АРТ на госпитальном этапе не повышало эффективность лечения туберкулеза, что, очевидно, было связано с медленным приростом клеток, не оказывающим существенного влияния на механизмы иммунной защиты при исходно низком содержании CD4. Присоеди- 
нение АРТ способствовало росту госпитальной летальности за счет развития воспалительного СВИС, наиболее опасным в этом плане было СВИС-ассоциированное поражение нервной системы. После выписки из стационара основными причинами фатального исхода были прогрессирование туберкулеза (неудача лечения, рецидивы) и других ВИЧ-ассоциированных инфекций, чему способствовало наличие мультирезистентности МБТ, выраженное угнетение Т-хелперного звена иммунитета и низкая приверженность к АРТ. Большое количество выживших лиц и эффективный рост CD4 у пациентов последнего, наиболее короткого периода наблюдения, свидетельствует о возможности эффективного излечения туберкулеза и контроля над ВИЧ-инфекцией даже при исходно выраженном иммунодефиците. Несмотря на высокий риск развития СВИС и его негативное влияние на эффективность стационарного этапа лечения, представляется целесообразным ранее присоединение АРТ больным ко-инфекцией ТБ/ ВИЧ с глубокой иммуносупрессией, поскольку в дальнейшем при условии адекватной антимикобактериальной химиотерапии, дисциплинированном приеме препаратов и применении современных схем АРТ возможно повышение выживаемости пациентов и достижение приближенных к физиологической норме показателей иммунитета.

\section{В Ы В 0 Д Ы}

1. После начала АРТ больным ко-инфекцией ТБ/ВИЧ с количеством CD4 менее 100 кл/мкл развитие воспалительного СВИС диагностировано у 34,5\% человек, при этом у 85,4\% пациентов происходило обострение туберкулезного процесса. Показатели госпитальной летальности составляли 14,4\%, в структуре всех причин смерти 70\% случаев занимал СВИС.

2. Через 5,5-7 лет после выписки из стационара в живых оставались 15,6\% больных, они были сняты с учета фтизиатра, не прерывали APT, имели неопределяемый уровень вирусной нагрузки и содержание CD4, приближенное к физиологической норме. Из больных, наблюдаемых в течение 4-5 лет, 53,3\% лиц не имели признаков активности ТБ, они продолжали АРТ, у 12 из 14 обследованных определялись показатели CD4 выше 100 кл/мкл и вирусной нагрузки ниже 50 РНК-копий/мл. Через 1-3 года после окончания госпитального этапа лечения в живых оставались 74,1\% больных, 90\% из них не прерывали APT, у 88,9\% концентрация ВИЧ в крови не превышала 50 РНК-копий/мл, у 84,2\% обследованных содержание CD4 превышало 100 кл/мкл.

3. Несмотря на повышенный риск развития СВИС, представляется целесообразным ранее присоединение АРТ больным ко-инфекцией ТБ/ ВИЧ с глубокой иммуносупрессией, поскольку при условии успешного излечения туберкулеза, непрерывном приеме и эффективной схеме АРТ повышается выживаемость пациентов, а показатели иммунитета приближаются к физиологической норме.

\author{
Е.В. Корж ${ }^{1}$, Н.А. Подчос ${ }^{2}$, Л.В. Стрига ${ }^{2}$, Т.С. Извекова ${ }^{3}$, Н.А. Малявко ${ }^{4}$ \\ ${ }^{1}$ ГОО ВПО «Донецкий национальный медицинский университет имени М. Горького», Донецк \\ ${ }^{2}$ Республиканская клиническая туберкулезная больнища, Донецк \\ ${ }^{3}$ Городской противотуберкулезный диспансер, Донецк \\ ${ }^{4}$ Городской противотуберкулезный диспансер, Макеевка
}

\title{
ВЛИЯНИЕ АНТИРЕТРОВИРУСНОЙ ТЕРАПИИ НА СОСТОЯНИЕ БОЛЬНЫХ КО-ИНФЕКЦИЕЙ ТУБЕРКУЛЕЗ/ВИЧ С ГЛУБОКОЙ ИММУНОСУПРЕССИЕЙ НА РАЗЛИЧНЫХ ЭТАПАХ НАБЛЮДЕНИЯ
}

Цель исследования - проанализировать влияние АРТ на состояние больных ко-инфекцией ТБ/ВИЧ с глубокой иммуносупрессией на различных этапах наблюдения.

Материалы и методы. Обследованы 139 больных ко-инфекцией ТБ/ВИЧ с содержанием CD4лимфоцитов менее 100 кл/мкл, находившихся на лечении в Республиканской клинической туберкулезной больнице г. Донецка в 2011-2018 гг. Медианы содержания CD4 составляли 33,2 кл/мкл - 4,2\%. Всем пациентам начинали химиотерапию туберкулеза, назначали АРТ, включающую 2 нуклеозидных и 1 ненуклеозидный ингибиторы обратной транскриптазы.
Судьбу пациентов, выбывших из стационара, проследили у 89 человек, период наблюдения - с января 2011 г. по май 2019 г.

Результаты и обсуждение. Присоединение АРТ сопровождалось развитием синдрома восстановления иммунной системы (СВИС) у $34,5 \%$ больных, при этом у $85,4 \%$ пациентов происходило обострение туберкулеза. Госпитальная летальность составила 14,4\% (20 больных), в 14 (70,0\%) случаях летальный исход наступил в результате СВИС. Выписаны для продолжения лечения амбулаторно 71,2\% больных, закончили полный курс химиотерапии 6,5\%. Из 32 человек, выписанных в 2011-2013 гг., до конца периода наблюдения 
в живых оставались пятеро (15,6\%), они не прерывали APT, медианы уровня CD4 составляли 502,0 кл/мкл - 28,5\%, вирусная нагрузка была менее 50 PHК-копий/ мл. Умерли $22(68,7 \%)$ пациента, из них $9(40,6 \%)$ - в течение первого года после выписки. Основной причиной смерти был туберкулез - 63,6\% случаев. Из 30 пациентов, выписанных в 2014-2015 гг., остались в живых и не имели активности туберкулезного процесса 53,3\%, они продолжали APT, содержание CD составляло 279,0 кл /мкл - 22,6\% вирусная нагрузка была менее 50 РНК-копий/мл. Умерли 10 (33,3\%) человек, в том числе трое - от туберкулеза. Из 27 лиц, выписанных в 2016-2018 гг., 20 (74,1\%) завершили противотуберкулезную химиотерапию и не имели признаков активности туберкулеза, из них 90,0\% не прерывали AРT, содержание CD4 составляло 369,0 кл/ мкл - 17,8\%, у 88,9\% вирусная нагрузка не превышала 50 РНК-копий/мл. Умерли шестеро (22,2\%): двое от МРТБ, и четверо - от ВИЧ-ассоциированных заболеваний.

Выводы. После начала АРТ больным ко-инфекцией
ТБ/ВИЧ с количеством CD4 менее 100 кл/мкл развитие воспалительного СВИС диагностировано у $34,5 \%$ человек, в 85,4\% случаев происходило обострение туберкулеза. Госпитальная летальность составляла $14,4 \%$, в структуре причин смерти $70 \%$ занимал СВИС. На амбулаторном этапе основной причиной смерти было прогрессирование туберкулеза и других ВИЧ-ассоциированных инфекций, чему способствовало наличие мультирезистентности МБТ, угнетение Т-хелперного звена иммунитета и низкая приверженность к АРТ. Наибольшее количество выживших и эффективный рост CD4 наблюдался среди пациентов последнего, наиболее короткого, периода наблюдения, что свидетельствует о возможности эффективного излечения туберкулеза и контроля над ВИЧинфекцией даже при изначально тяжелом иммунодефиците. Условиями благоприятного исхода является адекватная противотуберкулезная и антиретровирусная терапия, приверженность пациентов к лечению.

Ключевые слова: ВИЧ-инфекция, туберкулез, антиретровирусная терапия.

\section{E.V. Korzh ${ }^{1}$, N.A. Podchos ${ }^{2}$, L.V. Striga ${ }^{2}$, T.S. Izvekova ${ }^{3}$, N.A. Malyavko ${ }^{4}$}

${ }^{1}$ SEI HPE «M. Gorky Donetsk National Medical University», Donetsk ${ }^{2}$ Republican Clinical Tuberculosis Hospital, Donetsk

${ }^{3}$ Municipal Tuberculosis Dispensary, Donetsk

${ }^{4}$ Municipal Tuberculosis Dispensary, Makeyevka

\section{INFLUENCE OF ANTIRETROVIRAL THERAPY ON THE STATE OF PATIENTS WITH CO-INFECTION TUBERCULOSIS/HIV WITH ADVANCE IMMUNOSUPRESSION AT DIFFERENT STAGES OF OBSERVATION}

The aim of the study was to asses an influence of antiretroviral therapy in tuberculosis/HIV co-infected patients with advanced immunosupression on different periods of observation.

Materials and methods. One hundred thirty nine tuberculosis/HIV co-infected patients, which were treated in the Donetsk Republican clinical tuberculosis hospital in 2011-2018, were inspected. All patients had CD4 count less than 100 cells/mm3 (median 33,2 cells/mm3 - 4,2\%). The antituberculosis and antiretroviral therapy including 2 nucleotide/nucleoside and 1 non-nucleotide reverse transcriptase inhibitor was administered. The fate of 28 patients who left the hospital was traced. The observation period was from January 2011 for May 2019.

Results and discussion. The ART joining was accompanied by development of immune reconstitution inflammatory syndrome (IRIS) in $34,5 \%$ patients, in $85,4 \%$ patients there was aggravation of tuberculosis. Hospital lethality was $14,4 \%$ (20 patients), in $14(70,0 \%)$ persons the main cause of death was IRIS. $71,2 \%$ patients were discharge from the hospital for ambulatory treatment and $6,5 \%$ completed full course of the chemotherapy. From 32 the persons who were discharge from the hospital in 2011-2013, the five (15,6\%) survived. They did not interrupt ART, the medians of CD4 count was 502,0 cells $/ \mathrm{mm} 3$ $-28,5 \%$, the viral load was less than 50 RNA-copies $/ \mathrm{ml}$. $22(68,7 \%)$ patients died, from them $9(40,6 \%)$ - during the first year, the main reason of death was tuberculosis $-63,6 \%$ cases. From 30 the patients discharged in 2014$2015,53,3 \%$ remained living and had not activity of the tuberculosis, they continued ART, CD4 count was 279,0 cells/mm3 - 22,6\% the viral load was less than 50 RNAcopies $/ \mathrm{ml}$.

10 (33,3\%) persons died (three - from tuberculosis). From 27 the persons discharged in 2016-2018 20 (74,1\%) completed a antituberculosis chemotherapy and had not the activity of tuberculosis, from them $90,0 \%$ did not interrupt ART, the maintenance CD4 count was 369,0 cells/ $\mathrm{mm} 3-17,8 \%$, in $88,9 \%$ the viral load did not exceed 50 RNK- RNA-copies/ml. Six (22,2\%)persons died: two from MRTB, and four - from the HIV-associated diseases.

Conclusions. IRIS was diagnosed in $34,5 \%$ of tuberculosis/HIV co-infected patient with advanced immunosupression started with ART, there was aggravation of tuberculosis in $85,4 \%$ cases. Hospital lethality was $14,4 \%$, $70 \%$ of death reasons was occupied by IRIS. On an ambulatory stage the main cause of death was tuberculosis and other HIV-associated infections, they progressed because MBT multiply drag resistance, CD4 immunosupression and low adherence to the ART. Most of surviving and effective CD4 growth was observed among the patients of last, most short, period, that testifies to possibility of effective recovery from tuberculosis and control HIV-infection despite initially advanced immunodeficiency. Adequate antituberculosis and antiretroviral therapy, adherence of patients to medical treatment are the main conditions for positive outcome.

Key words: HIV-infection, tuberculosis, antiretroviral therapy. 


\section{ЛИТЕРАТУРА}

1. Унифицированный клинический протокол оказания медицинской помощи «ВИЧ-инфекция у взрослых и подростков». Приказ МЗ ДНР № 1374 от 07.08.2018 г. URL: http://mzdnr.ru/doc/prikaz-ob-utverzhdeniiunificirovannogo-klinicheskogo-protokola-okazaniyamedicinskoy-pomoshchi

2. Кравченко А.В., Зимина В.Н. Антиретровирусная терапия у больных ВИЧ-инфекцией и туберкулезом (обзор литературы). Инфекционные болезни: новости, мнения, обучение. 2012; (1): 15-22.

3. Blanc F.X., Sok T., Laureillard D., Borand L. et al. Earlier versus later start of antiretroviral therapy in HIV-infected adults with tuberculosis. Engl. J. Med. 2011; 365 (16): 1471-1481.

4. Корж Е.В., Подчос Н.А., Извекова Т.С., Малявко Н.А. Антиретровирусная терапия у ВИЧ-инфицированных больных туберкулезом с глубокой иммуносупрессией. Университетская клиника. 2017; 25 (4): 95-100..

5. van Bilsen, Ward P.H.; van den Berg, Charlotte H.S.B. et al. Immune reconstitution inflammatory syndrome associated with toxoplasmic encephalitis in HIV-infected patients. AIDS. 2017; 31 (10): 1415-1424. doi: 10.1097/ QAD.0000000000001492.

6. Walker N.F., Scriven J., Meintjes G., Wilkinson R.J. Immune reconstitution inflammatory syndrome in HIV-infected patients. HIV AIDS (Auckl). 2015; 7:49-64. doi: 10.2147/ HIV.S42328

7. Мордык А.В., Ситникова С.В., Пузырева Л.В. Влияние иммунного статуса, стадии и терапии ВИЧ-инфекции на исход стационарного этапа лечения у пациентов с сочетанной патологией ТБ/ВИЧ-инфекция. Инфекция и иммунитет. 2016; 6 (1): 81-86.

8. Захарова Н.Г., Дворак С.И., Плавинский С.Л., Торопов С.Э., Рассохин В.В., Беляков Н.А. Причины неблагоприятных исходов у больных с ВИЧ-инфекцией, принимавших ВАРТ. Часть 1.ВИЧ-инфекция и иммуносупрессии. 2015; 7 (3): 48-55. doi: 10.22328/2077-98282015-7-3-48-55

9. Лях Ю.Е., Гурьянов В.Г., Хоменко В.Н., Панченко О.А. Основы компьютерной биостатистики. Анализ информации в биологии, медицине и фармации статистическим пакетом MedStat. Донецк; 2006. 214.

\section{REFERENCES}

1. Unifitsirovannyi klinicheskii protokol okazaniya meditsinskoi pomoshchi «VICh-infektsiya u vzroslykh i podrostkov». Prikaz MZ DNR № 1374 ot 07.08.2018 g. URL: http:// mzdnr.ru/doc/prikaz-ob-utverzhdenii-unificirovannogoklinicheskogo-protokola-okazaniya-medicinskoy-pomoshchi (in Russian).

2. Kravchenko A.V., Zimina V.N. Antiretrovirusnaya terapiya $\mathrm{u}$ bol'nykh VICh-infektsiei i tuberkulezom (obzor literatury). Infektsionnye bolezni: novosti, mneniya, obuchenie. 2012; (1): 15-22 (in Russian).

3. Blanc F.X., Sok T., Laureillard D., Borand L. et al. Earlier versus later start of antiretroviral therapy in HIV-infected adults with tuberculosis. Engl. J. Med. 2011; 365 (16): 1471-1481.

4. Korzh E.V., Podchos N.A., Izvekova T.S., Malyavko N.A. Antiretrovirusnaya terapiya u VICh-infitsirovannykh bol'nykh tuberkulezom s glubokoi immunosupressiei. Universitetskaya klinika. 2017; 25 (4): 95-100 (in Russian).

5. van Bilsen, Ward P.H.; van den Berg, Charlotte H.S.B. et al. Immune reconstitution inflammatory syndrome associated with toxoplasmic encephalitis in HIV-infected patients. AIDS. 2017; 31 (10): 1415-1424. doi: 10.1097/ QAD.0000000000001492.

6. Walker N.F., Scriven J., Meintjes G., Wilkinson R.J. Immune reconstitution inflammatory syndrome in HIV-infected patients. HIV AIDS (Auckl). 2015; 7:49-64. doi: 10.2147/HIV.S42328

7. Mordyk A.V., Sitnikova S.V., Puzyreva L.V. Vliyanie immunnogo statusa, stadii i terapii VICh-infektsii na iskhod statsionarnogo etapa lecheniya $u$ patsientov s sochetannoi patologiei TB/VICh-infektsiya. Infektsiya i immunitet. 2016; 6 (1): 81-86 (in Russian).

8. Zakharova N.G., Dvorak S.I., Plavinskii S.L., Toropov S.E., Rassokhin V.V., Belyakov N.A. Prichiny neblagopriyatnykh iskhodov $u$ bol'nykh s VICh-infektsiei, prinimavshikh VART. Chast' 1.VICh-infektsiya i immunosupressii. 2015; 7 (3): 48-55. doi: 10.22328/2077-9828-2015-7-3-48-55 (in Russian).

9. Lyakh Yu.E., Gur'yanov V.G., Khomenko V.N., Panchenko O.A. Osnovy komp'yuternoi biostatistiki. Analiz informatsii v biologii, meditsine i farmatsii statisticheskim paketom MedStat. Donetsk; 2006. 214 (in Russian). 